\title{
ENTRE O REGIONALISMO E A CONSTRUÇÃO DA NAÇÃO: O IMPASSE DA ATUAÇÃO GAÚCHA NA CONSTITUINTE DE 1934, de Arilda Fortunada Arboleya ${ }^{1}$
}

Tabata Larissa Soldan ${ }^{2}$

- Enviado em 29/01/2016

- Aprovado em 24/02/2016

Com títulos muito bem pensados que tornam a leitura direcionada e uma escrita clara que possibilita ao leitor uma fluidez ao ler o texto, "Entre o regionalismo e a construção da Nação: O impasse da atuação gaúcha na Constituinte de 1934" é um trabalho caríssimo à área de Pensamento Social Brasileiro e um importante instrumento de auxílio à compreensão da nossa formação social.

Arilda Fortunata Arboleya em sua dissertação busca, como próprio título indica, compreender a participação da bancada gaúcha no processo constituinte de 1933/34. Procurando entender o comportamento desta neste cenário (como se dava sua atuação) e focando em como eram tratados pela bancada temas como identidade política regional (quais eram os interesses envolvidos, diante do receituário centralizador da época). Para isso a autora divide seu trabalho em quatro capítulos.

No primeiro capítulo é realizado um trabalho de contextualização do cenário geral de 1930, entendido como importante para compreendermos nosso processo de transição à modernidade. Na segunda parte do trabalho voltasse para a análise da Assembléia Nacional Constituinte, compreendida como uma arena de conflito entre os grupos de interesse da época. Já o terceiro e o

\footnotetext{
${ }^{1}$ Dissertação de autoria de Arilda Fortunata Arboleya, defendida no Programa de Pós-Graduação em Sociologia da UFPR, em 2010, sob orientação do Prof. Dr. Ricardo Costa de Oliveira. Versão completa disponível na Biblioteca Digital da UFPR

file://C:/Users/User/Downloads/Entre\%20o\%20Regionalismo\%20e\%20a\%20Construcao\%20da\%20Nacao\%20$\% 20$ o\%20impasse $\% 20$ da\%20atuacao\%20gaucha\%20na\%20Constituinte\%20de\%20193.pdf

${ }^{2}$ Mestre em Sociologia pela Universidade Federal do Paraná. Endereço eletrônico: tabatasoldan@yahoo.com.br
} 
quarto capítulos buscam esmiuçar a atuação do Rio Grande do Sul na Assembléia Nacional Constituinte de 1933/34, este entendido como um segmento de identidade regionalista.

Os anos 30 foram anos de transformações sócio-políticas e institucionais que faziam frente à herança colonial e buscavam a consolidação de uma sociedade moderna. A autora tem como seu objeto de pesquisa a Assembléia Nacional Constituinte de 33/34 que compreende como uma arena, e como tal, acredita que esta possibilita que se perceba a existência de relações de disputa entre diferentes grupos de interesses, presentes naquela sociedade. Por isso, de acordo com Arboleya (2010),

o estudo da Assembléia Nacional Constituinte de 1933/34, em todas as suas dimensões, impõe-se como instrumento de clarificação do embate de forças no momento em que, no agregado de transformações profundas, emergem no cenário político novos atores sociais representando novos setores economicamente produtivos, visto a crise do setor cafeeiro econômica e politicamente hegemônico até então (ARBOLEYA, 2010, p. 8).

Diante disso, utiliza como material de análise a Constituição de 1934 entendendo este como "um documento forjado num embate de forças sociais em luta pela consolidação de um projeto político hegemônico (no qual o jogo de interesses não permite falar de homogeneidade nem tão pouco de opressão rasa), e que produz efeitos sobre a sociedade que regulamenta" (ARBOLEYA, 2010, p. 12).

Assumindo uma perspectiva teórico-metodológica inserida numa abordagem macro-social a autora busca realizar uma análise interpretativa e crítica do objeto de pesquisa. Para isso utilizouse da técnica de Análise de Conteúdo para analisar os seguintes materiais: Anais da Assembléia Nacional Constituinte de 1933/34, Anteprojeto Constitucional (1933); Regimento interno da ANC; Diários da ANC de 1933/34; Constituição da República dos Estados Unidos do Brasil de 16 de julho de 1934; Código Eleitoral de 1932; Bibliografia geral pertinente (análise comparada da bibliografia sobre o tema).

Arboleya (2010) ressalta que a especificidade de seu trabalho consiste justamente no foco que faz da discussão do regionalismo/centralismo dentro do contexto da Constituinte de 33/34.

Voltando-nos ao que é trabalhado mais detalhadamente nos quatro capítulos da dissertação:

A autora divide em 3 partes o capítulo 1, "Um cenário de transição na sociedade brasileira", buscando de modo geral contextualizar seu objeto de pesquisa. Na primeira parte, "O Contexto Pré-30: preparando a cena", dedica-se a demonstrar quais fatores fizeram com que a 
política regionalista, até então vigente, começasse a entrar em decadência. Dando principal atenção ao processo de complexificação do tecido social.

\begin{abstract}
a Primeira República foi marcada pela fragilidade do poder central, pela inexpressividade dos partidos políticos, por um sistema político fechado e inacessível às forças alheias ao esquema político-econômico preponderante, por relações sociais clivadas por um padrão hierárquico excludente dado nas formas da sociedade rural. Todos os fatores de crise apontados, somados ainda ao processo de transformação subjacente da sociedade brasileira, agiram de forma contínua na derrocada das estruturas sociais e institucionais vigentes, conduzindo à quebra do sistema político pela fusão de vários grupos de contestação, que desencadearam o movimento revolucionário de 1930 (ARBOLEYA, 2010, p. 29).
\end{abstract}

A segunda parte do capítulo 1, “A Revolução de 1930: transição em curso”, foca no papel exercido pela Revolução de 30 na construção deste cenário de mudanças sociais e políticas pelas quais estava passando a sociedade brasileira. A autora compreende a revolução como um marco no processo político nacional, pois desencadeou profundas modificações, desde na posição dos atores políticos, até na base política de fundamentos do poder, referendada na alteração da ideologia sóciopolítica dominante.

Ainda nesta seção do capítulo, Arboleya (2010) realiza um estado da arte das diferentes interpretações teóricas dadas sobre a Revolução 30. Dentre os autores e correntes de pensamentos elencados citamos: Boris Fausto e a sua compreensão de que o movimento revolucionário seria mais adequadamente caracterizado como realocação das elites no poder; Edgar De Decca e a ideia que a revolução teve a luta de classes como seu fator propulsor, pois se fez necessário que a burguesia contesse a classe trabalhadora, que havia ganhado força política na década de 1920 quando passou a atuar organizada institucionalmente; e Virgílio Santa Rosa que identifica em 1930 uma Revolução Burguesa.

A última parte do primeiro capítulo, "O Cenário Pós-30: em busca de legitimação”, é dedicada a uma nova contextualização de cenário, àquele que se apresenta após a Revolução de 30, mais especificamente, o período da Constituinte de 33/34. De acordo com a autora, os pontos que emergem no pós-30, e são os mais significativos para o debate do período, são dois: "a tendência à consolidação de um Estado centralizador burocratizado e a insatisfação dos grupos regionais com essa estrutura estatal que tolhia a tradicional autonomia das elites dominantes em âmbito estadual" (ARBOLEYA, 2010, p. 40). Portanto, a Constituinte é compreendida pela autora como o espaço onde se refletia "o processo de transição em curso, apresentando-se como espaço de avaliação e legitimação institucional de concepções e práticas político-democráticas, econômicas e de reconfiguração das relações sociais". (ARBOLEYA, 2010, p. 42). 
No capítulo 2, "A Constituinte de 1934 e o cenário de transição em curso", é realizada uma análise mais pormenorizada da Constituinte de 34 , focando nos atores e nos interesses envolvidos, e nos temas que eram discutidos.

$\mathrm{Na}$ primeira seção, “Constituição, Constituinte, Constitucionalismo: demarcações conceituais", Arboleya (2010) descreve duas abordagens sobre Constituições e processos Constituintes objetivando explicar o porquê compreende a Constituinte como uma arena política, onde se apresentam lutas entre forças sociais, são elas: a perspectiva idealista, somada a uma abordagem descritiva e "as perspectivas que as concebem enquanto matéria e instrumento de consolidação hegemônica do poderio de um grupo social, aliadas à percepção destes documentos enquanto espelho do momento histórico vivido em dada sociedade e espaço de construção de uma pauta política que produz efeitos sócio-históricos" (ARBOLEYA, 2010, p.47). Apesar de assumir a segunda perspectiva, a autora considera que ambas devem ser levadas em conta, obviamente tomando os devidos cuidados, quando se trabalham com documentos como esses.

Na segunda parte do capítulo 2, "A Constituinte de 1934: características gerais", além da explicação detalhada que a autora realiza do longo processo pelo qual passou a reestruturação do aparelho institucional brasileiro do período, foram analisadas algumas características gerais da Constituinte de 33/34 e da Constituição derivada desta.

Promulgada em 16 de julho de 1934, a Constituição da República Nova é considerada, apesar de sua curta vigência (pois foi substituída em 1937 juntamente com a instituição do Estado Novo), um marco legal da transição pela qual passava a sociedade brasileira. Trazendo em seu texto alguns planos políticos que são considerados inovadores, como: Sufrágio universal, direto, secreto e obrigatório a homens e mulheres (quando estas exerciam função pública e remunerada); Legislação trabalhista que regulamentava salário, carga horária, férias remuneradas, indenização por demissão sem justa causa, licença maternidade, criação da previdência social (de fundo compartilhado entre União), etc; Assistência social com uma configuração avançada; Educação escolar primária como um direito básico de responsabilidade da União, Estados, Município e da família, gratuita e obrigatória, com o objetivo de fomentar uma moral social, a racionalidade econômica para o progresso e a formação de um "espírito de brasilidade" (Constituição da República Nova, art. 149, apud, ARBOLEYA, et al., 2012); etc.

Na última parte do segundo capítulo, “1934: a Constituinte e o cenário de transição no Brasil", a autora se aprofunda no posicionamento dos atores, nos interesses envolvidos e nos temas mais debatidos. De modo geral compreende que o conflito capital da Constituinte e do período pairava sobre as manifestações de amor à Nação e ao apego entusiasta à região, e que a temática do 
moderno aparecia repetidamente em quase todas as falas (apesar de muitas vezes possuir sentidos bastante distintos). Além disso, temas como justiça, assistência social, questão agrária, imigração, foram alguns dos que alcançaram maior projeção na Constituinte de 1933/34, revelando assim a heterogeneidade social presente naquele momento de transição e que configuram o espaço da Constituinte de 33/34 "como um espaço de enfrentamento entre grupos sociais, portadores de projetos de Brasil" (ARBOLEYA, 2010, p. 69).

Focando na discussão do regionalismo/centralismo dentro do contexto da Constituinte de 33/34, Arboleya (2010) se dedica a análise da bancada gaúcha nos dois últimos capítulos.

"O Rio Grande do Sul na Constituinte: implicativos conjunturais de sua atuação" é o terceiro capítulo do trabalho. Dividido em duas partes, na primeira, "Implicativos Políticos da Formação Sócio-Histórica Gaúcha”, além de trabalhar questões acerca da construção identitária gaúcha, caracterização feita sob elementos militares, heroicos e democráticos que compõe a base do regionalismo local, adentra em questões acerca da atuação do Rio Grande do Sul antes da revolução (Aliança Libertadora) e após (ANC 33/34).

O Rio Grande do Sul possuía um lugar importante entre àqueles que configuravam as novas forças dirigentes nacionais, principalmente o Partido Republicano Liberal (PRL), base de apoio do Governo Provisório, articulado em fins de 1932 após a ruptura com as tradicionais organizações partidárias do estado. Apresentou-se na ANC de 34 como "força legítima da ação renovadora da ordem político-social do país, e lá chegou com um peso particular" (ARBOLEYA, 2010, p. 88).

Por isso, na segunda parte do penúltimo capítulo, "Caracterização da Bancada Gaúcha", a autora se detém na configuração da bancada do Rio Grande do Sul, que era composta por: 16 deputados, 13 da base governista (PRL) e 3 da oposição (Frente Única Gaúcha - FUG) sendo a sexta maior representação estadual na Constituinte. Em geral a composição era essencialmente de proprietários rurais e profissionais urbanos, antigos chefes locais e jovens intelectuais. E se atenta também em como a bancada colocou diante do cenário da ANC de 34 e no papel conciliador que o PRL assumiu. A autora entende que este posicionamento "reflete a percepção que possuíam de que o projeto gaúcho, seus ideais políticos se fariam de qualquer maneira com a permanência de Vargas na presidência, ou mais que isso, que seu projeto era manter a posse da presidência”. (ARBOLEYA, 2010, p. 96).

No último capítulo do trabalho: "Um grupo e um projeto: os gaúchos entre a Nação e a região" a autora se questiona acerca do paradoxo que se apresenta na relação existente entre o protagonismo que o Rio Grande do Sul (um grupo regionalista, de tradição regionalista, de valores 
regionalistas) assumiu e propagandeou em um movimento que auxiliou no processo de ascensão da modernidade no Brasil.

Portanto, na primeira parte do capítulo, "Regionalismo e Centralismo: o impasse da atuação gaúcha na Constituinte", a autora se atém ao conteúdo geral das proposições gaúchas, que segundo ela "foi atravessado por um cunho federalista maquiado em transigências conciliatórias" (ARBOLEYA, 2010, p. 117 e 118). E teria sido, ao tratar operacionalmente as questões complementares à estrutura geral do Estado, que a bancada buscou solucionar o paradoxo que os acompanhava na Casa, dando assim um caráter incisivo de nacionalismo.

Na parte dois, "O Rio Grande do Sul e o Projeto Modernizador", Arboleya (2010) se aprofunda naquilo que ela compreende como o eixo do debate político na Constituinte em 34: o confronto estrutural regionalismo versus centralismo e que foi tangenciado pela temática de formatação de nação brasileira moderna, e em como a bancada gaúcha operacionalizou esta construção da modernidade nacional.

A configuração do sistema educacional foi o principal ponto que os gaúchos abordaram nesta perspectiva de fortalecimento da ideia de nação. De acordo com a bancada (apesar de algumas discrepâncias, tendo em vista que o PRL optou pelo receituário de progresso para a democracia, e a educação seria o aporte para alcançar tanto um quanto outro e a FUG, ao contrário, adotou a lógica da democracia para o progresso) investir em educação significava também investir em desenvolvimento econômico, o que permitiria a nacionalização da indústria e a fuga ao capital estrangeiro. Sendo assim, a educação seria "a própria criadora da personalidade brasileira". (ARBOLEYA, 2010, p.127).

Arboleya (2010) conclui, após uma detalhada análise da Constituinte de 33/34 e da atuação da bancada gaúcha nesta, que mesmo a despeito da fórmula para a modernização nacional do PRL: "educação para o desenvolvimento", que se converteu em força social ainda hoje vigente, não é possível que afirmemos ser esse segmento um portador do moderno, como ele mesmo se queria e se apresentava. Para a autora a identidade gaúcha na Constituinte foi a do interesse regional e a sua postura maleável e conciliatória, além de sua atuação mediana dividida entre o ideário centralista e o anti-centralista, foram medidas táticas para alcançar e manter regalias conquistadas no governo Vargas, "o Rio Grande foi mais um instrumento de um processo de transição social" (ARBOLEYA, 2010, p. 138).

A autora encerra seu texto ressaltando a importância de se analisar documentos como os derivados da Constituinte de 34, que a permitiu que observasse a correlação existente entre o processo histórico e uma leitura diferenciada sobre a formação institucional brasileira. 